\title{
Letters to EBD
}

RE: Commentary 'Weak evidence to support benefit of periodontal maintenance therapy in prevention of tooth loss. Evidence-Based Dentistry (2010) 11, 75-76

Professor Matthews writes a thoughtful commentary on this systematic review. There is one important clarification that is needed in relation to assessing risk of bias of non-randomised studies. In the latest version of the Cochrane Handbook ${ }^{1}$, the Newcastle-Ottawa scale is now one of the recommended methods for assessing such studies (section 13.5.2.3) and can be recommended to researchers conducting systematic reviews of non-randomised studies. Whilst Professor Matthews is right to be cautious of composite scales, the Newcastle-Ottawa scale can also be presented to show the individual components, overcoming the concerns of summary values.

Assessing risk of bias for non-randomised studies is not as well developed as for randomised trials. Nevertheless such an evaluation can and should be undertaken, particularly for oral health, as there is a wealth of such research that contains potentially important evidence for oral healthcare.

\section{lan Needleman, London}

1. Higgins JPT, Green S (editors). Cochrane Handbook for Systematic Reviews of Interventions Version 5.0.2 [updated September 2009]. The Cochrane Collaboration, 2009. Available from www.cochrane-handbook.org.

Send your letters to the Editor c/o Kim Black-Totham Evidence-Based Dentistry Nature Publishing Group The Macmillan Building 4 Crinan Street London N1 9XW

E-mail: ebd@nature.com

\section{News}

\section{AGREE trust launches updated website}

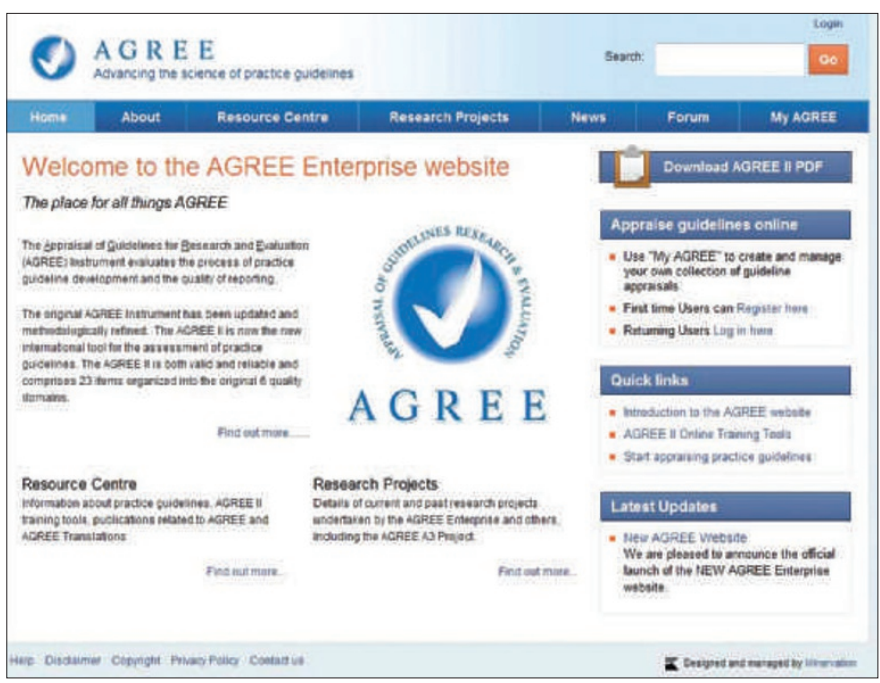

The AGREE (Appraisal of Guidelines for Research and Evaluation) trust has recently updated its website http://www.agreetrust.org (figure 1). The new site, referred to as the AGREE Enterprise website on its home page, is the location for all things AGREE. The AGREE Enterprise being an international endeavour to improve the quality of practice guidelines.

The original AGREE Instrument, for the appraisal of guidelines was published in 2003 by a group of international developers and researchers, the AGREE Collaboration. The instrument has been further developed and the revised instrument, AGREE II, can be downloaded from the site. The new website has links to the original AGREE Instrument as well as the updated version. There are two training tools for AGREE II in development, a tutorial and practical exercise that will be available soon.
By registering with the website in the 'My AGREE' area you will be able to conduct guideline appraisals online saving them for future reference creating your own personal library of practice guideline appraisals. The site also includes a forum for online discussion.

\section{SIGN plans update of caries guidance}

The Scottish Intercollegiate Guidelines Network (SIGN) has recently updated its current work programme (www.sign.ac.uk/guidelines/ development/index.html). The programme indicates that two of the existing dental guidance documents, SIGN 47- Preventing Dental Caries in Children at High Caries Risk, targeted prevention of dental caries in the permanent teeth of 6-16 year olds presenting for dental care (www.sign.ac.uk/guidelines/fulltext/47/index.html) and SIGN 83 - Prevention and management of dental decay in the pre-school child (www.sign.ac.uk/guidelines/fulltext/83/index.html) published in 2000 and 2005 respectively will undergo updating and be combined as a single guideline.
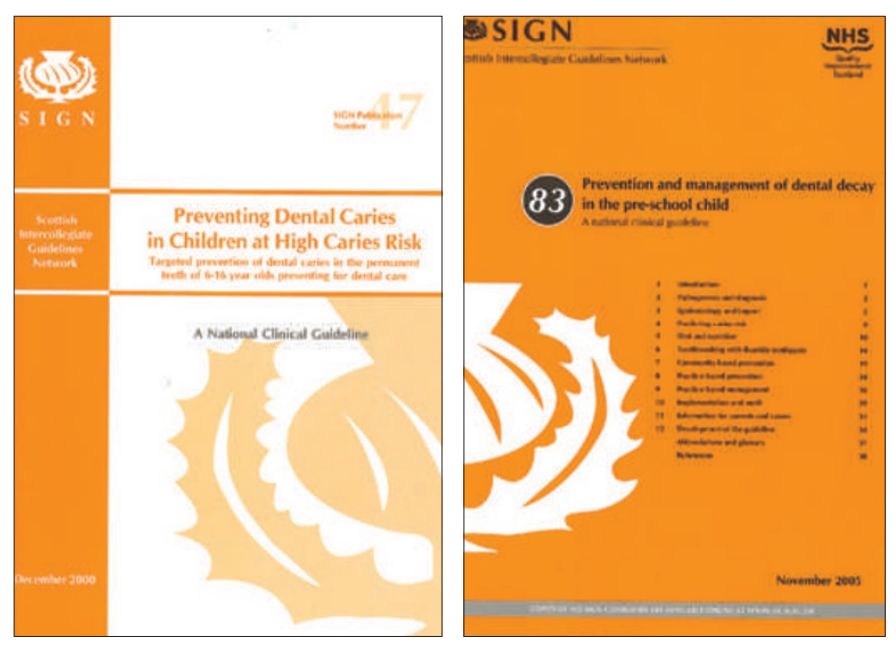